\title{
SAVREMENA REŠENJA IZGRADNJE SISTEMA ZA TRETMAN OTPADNIH VODA NA PRIMERU PPOV ŽITIŠTE
}

\section{MODERN SOLUTIONS FOR THE CONSTRUCTION OF A WASTEWATER TREATMENT SYSTEM ON THE EXAMPLE OF WWTP ŽITIŠTE}

\author{
Nataša Nikolin, Fakultet tehničkih nauka, Novi Sad
}

\begin{abstract}
Oblast - GRAĐEVINARSTVO
Kratak sadržaj - U okviru rada predstavljene su konvencionalne $i$ savremene metode prečišćavanja otpadnih voda. Cilj rada je analiza prednosti $i$ nedostataka savremenih metoda prečišćavanja otpadnih voda u odnosu na konvencionalne, i primena SBR metode prečišćavanja na PPOV Žitište.
\end{abstract}

Ključne reči: Metode prečišćavanja otpadnih voda, $P P O V, S B R$

\begin{abstract}
The paper presents conventional and modern wastewater treatment methods. The aim of this paper is to analyze the advantages and disadvantages of modern wastewater treatment methods compared to conventional ones, and the application of the SBR treatment method at WWTP Zitiste.
\end{abstract}

Keywords: Wastewater treatment methods, WWTP, SBR

\section{UVOD}

Bez vode nema života, a čovek je ipak koristi veoma neodgovorno i ne uviđa da ovaj resurs nije nepresušan. Mnoge kompanije se odnose neodgovorno prema prirodi i ispuštaju velike količine neprečišćene otpadne vode $u$ prirodne vodotoke, a sa druge strane, stanovništvo nije dovoljno edukovano o mogućim posledicama nepravilnog odlaganja zagađujućih, otrovnih i opasnih materija, pa se često ove materije nađu u otpadnim vodama i ugrožavaju celokupan živi svet.

Otpadna voda mora biti prečišćena da bi se ponovo vratila u prirodu, i prilagođena recipijentu na taj način da ne remeti prirodni balans samoj reci.

\section{OTPADNE VODE}

$\mathrm{Ne}$ postoji tačna definicija otpadne vode, međutim, ukoliko želimo da definišemo termin otpadne vode, možemo je definisati na sledeći način:

Voda onečišćena na bilo koji način tokom upotrebe predstavlja otpadnu vodu. U opštem slučaju voda je onečišćena rastvorenim i nerastvornim, organskim i neorganskim materijama i mikroorganizmima [2].

\section{NAPOMENA:}

Ovaj rad proistekao je iz master rada čiji mentor je bio dr Srđan Kolaković, red. prof.

\subsection{Zagađivanje vode}

Do zagađenja vode dolazi direktnim i indirektnim putem.

- Direktno zagađivanje vode

Zagađivanje voda direktnim putem se odvija putem industrijskih i komunalnih odvoda. Otpadne vode često sadrže štetne materije, otrovne supstance, naftne derivate, deterdžente, otpadna ulja, patogene organizme. Ovakve vode se direktno izlivaju u rečne tokove i zagađuju ih. Otpadne vode u kojima ima mnogo nitrata i fosfata utiču na prekomerno razmnožavanje algi i dovode do cvetanja vode koje ima za posledicu umiranje vodenih organizama zbog nedostatka kiseonika u vodi [1].

- Indirektno zagađivanje vode

Zagađivanje voda indirektno se odvija putem spiranja štetnih materija iz zemljišta pomoću padavina. Zagađujuće materije na ovaj način dolaze do podzemnih voda i šire se procesima prirodnog kruženja vode [1]. Do indirektnog zagađivanja vode dolazi usled loše poljoprivredne prakse, eksploatacije nafte i gasa, eksploatacije peska, šljunka i gline, putem divljih deponija, od saobraćaja itd.

\subsection{Sastav otpadne vode}

U opštem slučaju voda je onečišćena rastvorenim i nerastvornim, organskim i neorganskim materijama i mikroorganizmima. Najveći procenat $(99,9 \%)$ otpadne vode po masi čini voda [7]. Manji deo otpadne vode čine čvrste materije koje delimo na organske (70\%) i neorganske (30\%).

Sva zagađenja u vodi javljaju se u obliku rastvora, koloida i suspenzija. Zagađivači mogu biti organskog, neorganskog (mineralnog) ili mešovitog porekla. Zagađivači organskog porekla su poreklom od ljudi, biljaka i životinja, dok u neorganske (mineralne) zagađivače spadaju površinski sedimenti, zemljište, rastvorene mineralne soli i metali, pesak, glina, baze, kiseline, itd.

\subsection{Klasifikacija otpadnih voda}

Različite otpadne vode potrebno je prečišćavati u različitim postrojenjima. Otpadne vode možemo podeliti u tri grupe:

1. komunalne otpadne vode

2. industrijske otpadne vode

3. otpadne vode agro kompleksa 


\subsection{Tipovi graničnih koncentracija}

Osnovu upravljanje kvalitetom voda u svetskoj praksi čine dva tipa graničnih koncentracija:

1. Odnosi se na kvalitet voda u vodoprijemnicima (stream standards)-voda se može ispuštati sve dok se ne prekorače propisane granične vrednosti MDK-maksimalno dozvoljene koncentracije kvaliteta za vodu vodoprijemnika.

2. Odnosi se na ispuštenu-otpadnu vodu (effluent standards)-tj.na njen kvalitet GVE-granična vrednost emisije.

Danas se $\mathrm{u}$ svetu primenjuje kombinovani pristup $\mathrm{u}$ upravljanju vodama koji je u osnovi Okvirne Direktive o vodama (Framework Directive 2000/60/EC) koji podrazumeva kontrolu emisije i uspostavljanje standarda kvaliteta okoline primenjujući obe pomenute metodologije, odnosno, oba tipa graničnih koncentracija.

U Srbiji je u proteklom periodu primenjivan tip graničnih vrednosti za kvalitet voda vodoprijemnika, međutim ova metodologija može odgovarati svojoj nameni na malim vodotocima i proračun uticaja otpadnih voda na vodotok računa se za niske vodostaje jer je tada delovanje otpadnih voda najizrazitije [2].

\section{TRETMAN OTPADNIH VODA}

\subsection{Metode prečišćavanja voda}

Metode prečišćavanja vode se stalno usavršavaju. Ne postoji univerzalna procedura prečišćavanja vode koja bi bila odgovarajuća za svako postrojenje. Odabir adekvatne procedure zavisi od karakteristika otpadne vode kao i od željenog stepena prečišćavanja.

Postoje mehaničke, biološke i hemijske metode prečišavanja.

\subsubsection{Mehaničke metode}

Mehaničke metode podrazumevaju uklanjanje fizičkih nečistoća iz vode i zasnivaju se na delovanju fizičkih sila (gravitacija, pritisak) [1]. Koriste se: rešetke i sita, taloženje, flotacija, filtriranje, centrifugiranje, taložnici za pesak, hvatači masti, primarni taložnici i bazeni za izjednačavanje protoka.

\subsubsection{Biološke metode}

Biološke metode se zasnivaju na prirodnim zakonitostima i aktivnostima živih bića. Podrazumevaju prečišćavanje otpadnih voda putem mikroflore koja zagađujuće materije u otpadnim vodama usvaja tokom svog životnog ciklusa. Ova metoda ne prečišćava otpadnu vodu u potpunosti, ali je adekvatna za eliminisanje organskog zagađenja. Primenjuje se kao sekundarna obrada otpadne vode, nakon primarnog prečišćavanja putem mehaničkih metoda, ali i kao nezavisna metoda za prečišćavanje [1].

\subsubsection{Hemijske metode}

Hemijske metode podrazumevaju prečišćavanje otpadnih voda putem aditivnih procesa, odnosno hemikalija koje se dodaju u vodu i koje kroz hemijske reakcije uklanjaju zagađujuće materije. Prečišćavanje vode hemijskim putem je skupo, ali ponekad nema alternativu. Metode koje se koriste za hemijsko prečišćavanje vode su: hemijsko taloženje, jonska izmena, oksidacija, produvavanje gasom, adsorpcija [1]. Prednost ove metode je jednostavna i sigurna kontrola procesa, postrojenja se lako zaustavljaju i ponovo puštaju u rad bez uticaja na proces prečišćavanja.

Hemijske metode prečišćavanja otpadnih voda su slabije efikasnosti u odnosu na druge metode jer se rastvorene materije ne uklanjaju, povećava se količina taloga i mulja, a njihova obrada je skupa [1].

\subsection{Prirodni sistemi za prečišćavanje otpadnih voda}

Sve više se teži korišćenju sistema za prečišćavanje koji su jeftiniji, održivi, efikasniji, i zasnovani na ekološkim principima i tehnologijama koje predstavljaju prirodne sisteme prečišćavanja otpadnih voda. Pod ekološkim karakteristikama tehnologije podrazumevamo sposobnost oporavka resursa i njihovo ponovno korišćenje (vode i hranljivih materija) uz minimalnu upotrebu energije i hemikalija, ili potpuno izbacivanje iz upotrebe istog.

Jedna od glavnih prednosti prirodnih sistema je upravo minimalna upotreba energije jer se najveći deo energije uzima iz prirodnog okruženja. Međutim, da bi se ovakvi sistemi dobro isprojektovali, neophodno je multidisciplinarno znanje i tim stručnjaka različitih profila. Ovi sistemi se projektuju posebno za određenu lokaciju, za koju je neophodno znati njene geografske, mikroklimatske i ostale karakteristike, sa pažljivo izabranim i dimenzionisanim postrojenjem za prethodnu obradu otpadnih voda.

Iz ovih razloga, široj primeni prirodnih sistema za prečišćavanje otpadnih voda ne može se prići bez prethodnog sveobuhvatnog i dugotrajnog praćenja pilot postrojenja.

Za mala naselja (grupa naselja sa manje od 5000ES) preporučuju se prirodni sistemi prečišćavanja (Natural Treatment Systems), i u najvećem broju slučajeva to su sistemi za prečišćavanje zemljištem [3] . Ovakvi sistemi su danas vladajući u svetskoj praksi, i u te sisteme ubrajamo:

-navodnjavanje zemljišta otpadnom vodom (slika 1)

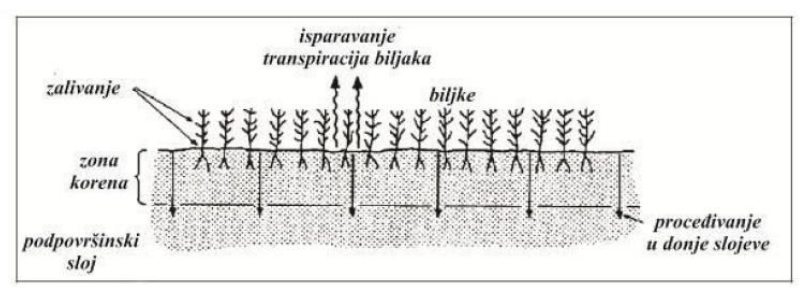

Slika 1. Prečišćavanje navodnjavanjem zemljišta [3] -infiltracija otpadnih voda kroz zemljište - prelivanje zemljišta otpadnom vodom (slika 2)

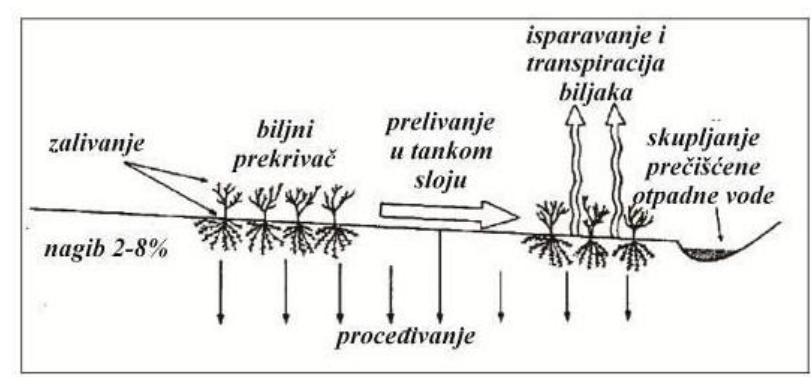

Slika 2. Prečišćavanje prelivanjem zemljišta [3] 


\subsection{SBR tehnologija prečišćavanja}

SBR (eng. Sequencing Batch Reactor) je tehnološki postupak biološkog prečišćavanja otpadnih voda sa aktivnim muljem $\mathrm{u}$ akumulirajućem postupku. SBR tehnologija prečišćavanja ima poseban značaj i primenu za sekundarni i tercijarni tretman otpadnih voda $\mathrm{tj}$. na biološku fazu tretmana. Prečišćavanje otpadnih voda primenom SBR tehnologije može se naći u mnogim evropskim zemljama [6].

SBR sistemi prečišćavanja otpadnih voda su u skorije vreme najzastupljeniji pri izgradnji novih manjih postrojenja za prečišćavanje otpadnih voda. Tehnologija se od konvencionalnih tehnologija biološkog prečišćavanja otpadnih voda razlikuje na razne načine. Glavnu razliku predstavlja to što zapremina ispunjenosti reaktora varira sa vremenom,a kod tradicionalnih sistema protok je kontinualan [4]. Radi se o klasičnoj metodi tretmana otpadnih voda sa aktivnim muljem i dubinskom aeracijom, ali sa modifikovnim objektom za biološki tretman, pri čemu se tri glavne tehnološke operacije odvijaju u jednom građevinskom objektu, a time se postiže značajna ekonomska i prostorna racionalizacija postrojenja [5]. Ciklus u SBR reaktoru odvija se u sledećim fazama: punjenje, mešanje, aeracija, taloženje, odlivanje (slika 3 ).

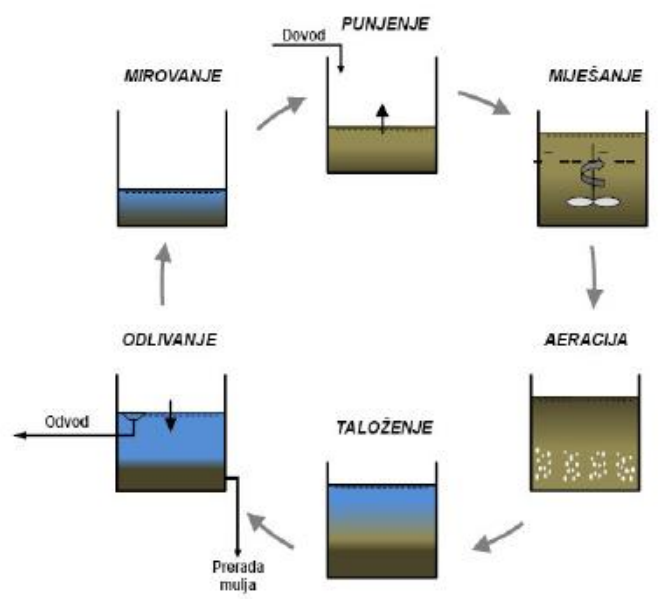

Slika 3. SBR ciklus [4]

\section{PPOV OPŠTINE ŽITIŠTE}

Primena SBR tehnologije urađena je na primeru prečišćivača otpadnih voda opštine Žitište. Opština Žitište je jedna od opština u Republici Srbiji. Nalazi se u AP Vojvodina i spada u srednjobanatski okrug. Opština Žitište se sastoji od 12 naselja. Prečišćivač će prečišćavati otpadnu vodu za naselja Banatski Dvor, Ravni Topolovac, Torak i Žitište. U radu je dato i rešenje spajanja kolektora na zajedničke prečišćivače za prečišćavanja otpadnih voda ostalih naselja Opštine Žitište.

Za potrebe proračuna hidrauličkog opterećenja, koje predstavlja ukupnu maksimalnu količinu otpadne vode $\mathrm{u}$ vršnom času i merodavno je za dimenzionisanje objekata postrojenja, korišćena je vrednost specifične količine otpadne vode $\left(\mathrm{q}_{\text {spec }}\right)$ od 150 1/st.dan. Specifična količina otpadne vode predstavlja očekivanu količinu otpadne vode po stanovniku u planskom periodu. Prečišćivač će se graditi u dve faze, za 4000+4000 ES (ukupno 8000 ES).
Hidrauličko opterećenje računa se preko izraza (1).

$$
Q s r=E S \cdot q_{s p e c}
$$

ES- ekvivalent stanovnika

Potrošnja vode nije konstantna $u$ toku dana, pa se za proračun hidrauličkog opterećenja uvode koeficijenti dnevne i časovne neravnomernosti.Usvojene su vrednosti:

$\mathrm{Kh}=1.5 \quad \mathrm{Kd}=2.0$

Srednje dnevno hidrauličko opterećenje:

Qsr $=600+600=1200 \mathrm{~m}^{3} /$ dan

Maksimalno dnevno hidrauličko opterećenje:

$Q_{\text {DW }, \mathrm{d}}=960+960=1920 \mathrm{~m}^{3} /$ dan

Maksimalno časovno hidrauličko opterećenje:

$\mathrm{Q}_{\text {DW, }}=80+80=160 \mathrm{~m}^{3} / \mathrm{h}$

$\mathrm{Za}$ sprovođenje tehnološkog postupka predviđena je odgovarajuća oprema za čiji se smeštaj predviđa izgradnja sledećih objekata: merač protoka sirove vode, aerisani peskolov sa hvatačem masti i sitom, egalizacioni bazen, SBR1 i SBR2 bazen (SBR3 i SBR4 bazeni u II fazi), aerobni digestor, pogonska zgrada, crpna stanica sanitarne vode, merač protoka prečišćene vode, izlivna građevina u recipijent.

\subsection{Linija vode}

Za obezbeđenje zahtevanog kvaliteta prečišćene vode predviđena je primena kombinovanog postupka mehaničko-biološkog prečišćavanja. Mehaničko prečišćavanje obuhvata odvajanje krupnih nečistoća na finoj rešetci, odvajanje peska i masnoće u aerisanom peskolovuhvataču masti. Nakon mehaničkog prečišćavanja sledi biološki postupak prečišćavanja sa cikličnom tehnologijom. Ovo podrazumeva uklanjanje ugljeničnog organskog zagađenja, nitrifikaciju azotnih jedinjenja i denitrifikaciju u SBR reaktorima (aeracioni bazen sa integrisanom funkcijom naknadnog taložnika) sa diskontinualnim dovodom i odvodom. Uporedo sa navedenim postupkom odvija se određena simultana kao i biološka defosforizacija. S obzirom na to da se, navedenom simultanom i biološkom defosforizacijom ne postižu uvek zadate granične vrednosti, projektom je predviđena $\mathrm{i}$ dodatna hemijska defosforizacija. Povremenim zaustavljanjem aeracije i mešanja, odigrava se razdvajanja faza taloženjem. Izbistrena-prečišćena voda se izdvaja u gornjem sloju SBR bazena, odakle se odvodi dekantacijom i nakon merenja količine ispušta u recipijent.

\subsection{Linija mulja}

Cilj obrade mulja je dostabilizacija i smanjenje zapremine, odnosno sadržaja vode u mulju. Višak mulja iz SBR reaktora pomoću potopljenih muljnih pumpi se potiskuje $u$ aerobni digestor gde se vrši dostabilizacija i zgušnjavanje. Zgušnjavanje mulja se postiže povremenim zaustavljanjem aeracije i mešanja, radi razdvajanja faza taloženjem. Deo izbistrene vode iz gornjeg sloja se odvodi dekantacijom i vraća se na ponovnu obradu. Stabilizovani mulj se uronjenom muljnom pumpom potiskuje na dekanter centrifugu sa usputnim doziranjem polielektrolita. Efikasno mešanje polielektrolita sa muljem se obezbeđuje u statičkom mešaču. Za pripremu i doziranje polielektrolita predviđen je jedan kompaktni automatski uređaj. Odvodnjavanje mulja predviđa se putem statičke centrifuge. Dispozicija muljne pogače iz centrifuge vrši se 
direktno u kontejner. Kontejneri sa muljnom pogačom se odvoze kamionima do krajnjeg odredišta.

Krajnja dispozicija muljne pogače je na deponiju. Proceđena voda se iz mašine odvodi preko interne kanalizacije na ponovnu obradu. Šema prečišćavanja za I fazu izgradnje prikazana je na slici 4 .

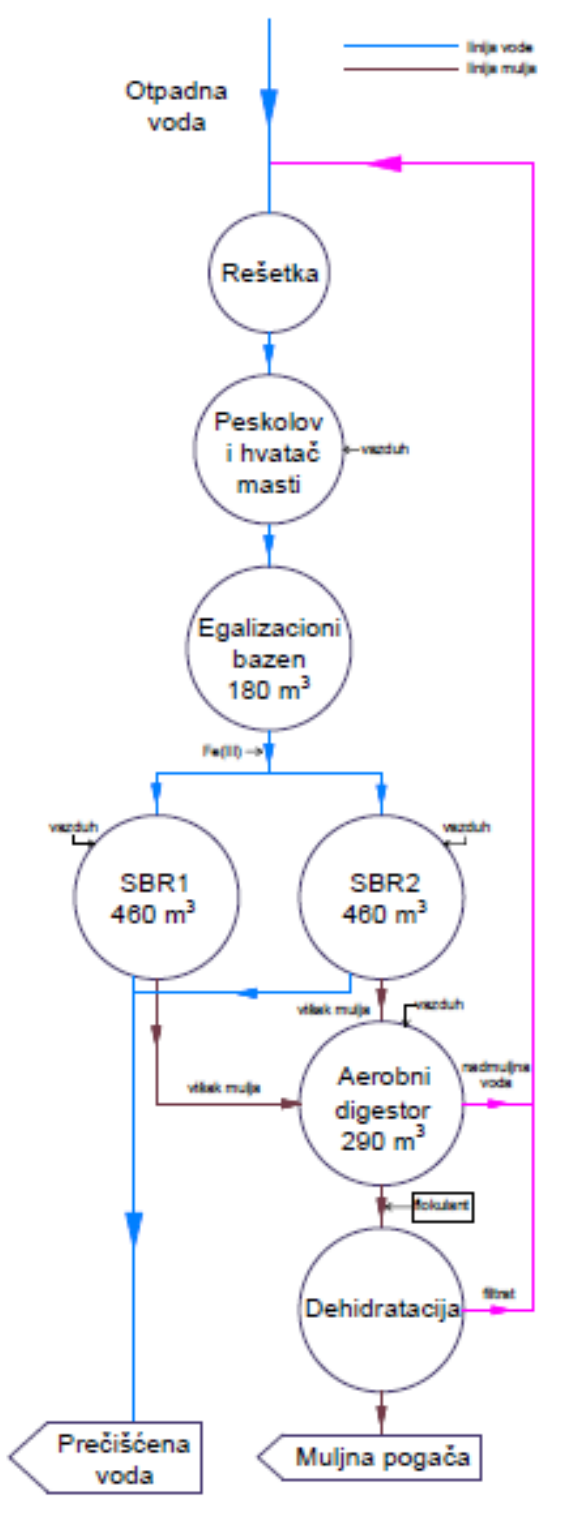

Slika 4. Šema prečišćavanja

\section{ZAKLJUČAK}

Pitanje količine i kvaliteta vodnih resursa jedan je od ključnih problema društva. Kroz sve faze razvoja društva, voda predstavlja nezaobilaznu komponentu biološkog, ekonomskog i socijalnog napretka, i usled stalnog porasta broja stanovnika potreba za prečišćavanjem otpadnih voda raste.

Prirodni sistemi za prečišćavanje otpadnih voda predstavljaju jednostavne sisteme za upravljanje i održavanje, i upravo to ih čini konkurentnim u odnosu na konvencionalne metode prečišćavanja otpadnih voda.
SBR proces je vrlo prilagodljiv proces, vreme trajanja procesa, koncentracija kiseonika i vreme mešanja može se prilagođavati potrebama postrojenja. Ima veoma visok stepen prečišćavanja, i do $99 \%$, izuzetno je pogodan za postrojenja srednjih kapaciteta, i po gabaritima zauzima znatno manje prostora u poređenju sa drugim sistemima. Nedostatak može predstavljati znatna automatizovanost sistema.

Predstavljeno rešenje PPOV Žitište ima kapacitet da prihvati i obradi otpadne vode koje nastaju od stanovništva. Postrojenje je tako koncepcijski rešeno da zadovolji sve zakonske uslove za ovakve uređaje, potrebne i neophodne uslove zaštite životne sredine, naročito vodeći računa o zaštiti podzemnih voda, recipijenta i zemljišta.

Fizičke, hemijske i biološke karakteristike prečišćene otpadne vode i dobijenog tretiranog mulja zadovoljavaju sve zahteve predviđene domaćim propisima i evropskim direktivama iz oblasti prečišćavanja otpadnih voda.

\section{LITERATURA}

[1] Kitanović R., Šušteršić V. (2013), Tretman otpadnih voda, Vojnotehnički glasnik Vol. LXI No.3: 122-140.

Ministarstvo odbrane Republike Srbije, Beograd

[2] http://www.cecra.dh.pmf.uns.ac.rs/pdfww2008/Otpadne\%20vodeemisinoni $\% 20$ standardi\%20i\%20odabir\%20tehnologije $\% 20$ za\%20vodotoke\%20sa\%20niskim\%20ekoloskim\% 20potenciojal.pdf (pristup: 15.10.2020)

[3] Nikolić, D., Skerlić, J., Šušterić, V. (2012), Sistemi za prečišćavanje otpadnih voda u velikim i malim naseljima, Fakultet inženjerskih nauka, Univerzitet $u$ Kragujevcu

[4] Cvetković, D., Despotović, M. (2011), Primena SBR sistema u prečišćavanju komunalnih otpadnih voda sa parametarskim modelom postrojenja, Mašinski fakultet u Kragujevcu

[5] Sudar, N., Perić, M., Đokić-Vasić, D. (2012), Postrojenje za prečišćavanje otpadnih voda Bileća po SBR tehnologiji-realizacija i efekti prečišćavanja, Institut za vode, Bjeljina

[6] Tulenčić, M., Stipić, M., Kolaković, S. (2015), Primena SBR tehnologije prečišćavanja otpadnih voda za naselja do 15000 ES, Međunarodna konferencija, Savremena dostignuća u građevinarstvu, Subotica [7] Stipić, M., (2016), Pisana predavanja iz predmeta komunalna hidrotehnika-Interna publikacija, Novi Sad

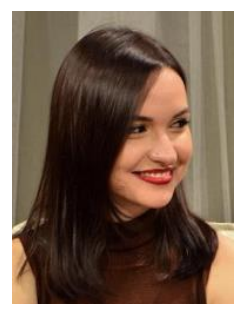

Nataša Nikolin rođena je u Zrenjaninu 1991. god. Master rad na Fakultetu tehničkih nauka iz oblasti Građevinarstvosmer Hidrotehnika, odbranila je 2020.god. kontakt: natasanikolin@ hotmail.com 